\title{
ANALISIS FAKTOR-FAKTOR PEKERJAAN TERHADAP TINGKAT KEMANGKIRAN KARYAWAN OPERASIONAL PT. ANEKA TUNA PASURUAN
}

\author{
Muhammad Anang Firmansyah, Phonny Aditiawan Mulyana \\ Faculty of Economics and Business, Muhammadiyah University,Surabaya Indonesia
}

\begin{abstract}
The purpose of this study is to determine the effect of work factors on the level of absenteeism of operational employees of PT Aneka Tuna Pasuruan. Job factors are breadth, stress, work style, leadership style, relationships between employees, opportunities to develop, reward / incentive systems, group norms work, and commitment to the organization. Impotence behavior developed from low work morale in organizational processes for work is also low, in addition to things that cannot be avoided (sickness, traffic trauma). PT. Aneka Tuna Pasuruan is one of the exporters of canned tuna in Indonesia, which has hundreds of employees, also inseparable from labor issues. In several years at PT. Aneka Tuna Pasuruan a high level of absenteeism from its employees. The level of absenteeism occurred at PT. Aneka Tuna Pasuruan, this is the very thing that the company is publishing. The results of the study state that work factors have a significant influence on the level of absenteeism of Operational employees at PT. Aneka Tuna Pasuruan Where the main factors have a dominant influence from other factors, on the absenteeism of employees at PT. Aneka Tuna Pasuruan.
\end{abstract}

$\begin{array}{ll}\text { Keywords } & : \text { Job factors, level of absenteeism } \\ \text { Correspondence to } & : \text { anang.firmansyah@fe.um-surabaya.ac.id }\end{array}$

\section{ABSTRAK}

Tujuan penelitian ini untuk mengetahui pengaruh faktor-faktor pekerjaan terhadap tingkat kemangkiran karyawan operasional PT Aneka Tuna Pasuruan.Faktor-faktor pekerjaan adalah keluasan pekerjaan, stres peran, ukuran kelompok kerja, gaya kepemimpinan, hubungan antar karyawan, kesempatan untuk berkembang, sistem imbalan/insentif, norma kelompok kerja, dan komitmen pada organisasi. Perilaku kemangkiran berkembang dari moral kerja yang rendah dalam suatu organisasi sehingga untuk datang kerja juga rendah, selain hal-hal yang tak bisa dihindari (sakit, kecelakaan lalu lintas). PT. Aneka Tuna Pasuruan merupakan salah satu perusahaan pengekspor ikan tuna dalam kaleng di Indonesia yang mempunyai ratusan karyawan, juga tidak terlepas dari masalah ketenagakerjaan. Pada beberapa tahun belakangan ini PT. Aneka Tuna Pasuruan mengalami tingkat kemangkiran yang tinggi dari karyawannya. Tingkat kemangkiran tersebut terjadi pada PT. Aneka Tuna Pasuruan, sehingga hal ini sangat mengganggu jalannya perusahaan. Hasil penelitian menyatakan bahwa faktor-faktor pekerjaan mempunyai pengaruh yang bermakna terhadap tingkat kemangkiran karyawan Operasional di PT. Aneka Tuna Pasuruan Sedangkan faktor Keluasan pekerjaan mempunyai pengaruh yang dominan daripada faktor-faktor lain, terhadap kemangkiran karyawan di PT. Aneka Tuna Pasuruan.

$\begin{array}{ll}\text { Kata kunci } & \text { : Faktor-faktor pekerjaan, Tingkat kemangkiran } \\ \text { Korespondensi } & \text { : anang.firmansyah@fe.um-surabaya.ac.id }\end{array}$ (a).um-surabaya.ac.ic 


\section{PENDAHULUAN / INTRODUCTION}

Sudah menjadi suatu norma bagi seorang manajer di suatu perusahaan, baik perusahaan besar maupun kecil untuk selalu berorientasi pada pencapaian tujuan secara efisien dan efektif, yakni menjalankan suatu organisasi yang memiliki daya saing dalam hal mutu, harga dan ketersediaan produk/jasa. Dengan profesionalisme mereka yang tinggi diharapkan mampu mengembangkan teknikteknik, metode-metode baru dan ketrampilan untuk mengantisipasi setiap perubahan yang terjadi.

Untuk mencapai tujuan tersebut perusahaan perlu memperhatikan keberadaan karyawan yang bekerja, seperti kebutuhan, kesetiaan, kecakapan dan kemampuan bekerja, karena hal-hal inilah yang bisa menjadi pendorong bagi karyawan dalam melakukan kegiatan yang pada gilirannya akan menguntungkan perusahaan. Adanya ketidaksesuaian antara kebutuhan dan pemenuhannya dapat menimbulkan masalah, baik bagi karyawan maupun perusahaan. Rendahnya gaji, lingkungan kerja yang tidak mendukung, beban kerja yang berlebihan dapat membuat karyawan kurang produktif dan rendahnya loyalitas. Akibatnya, disamping pemutusan hubungan yang permanen dari kegiatan organisasi (perpindahan pekerja), seorang pekerja cenderung memilih absen/mangkir atau tidak masuk kerja.

Kemangkiran juga berkaitan erat dengan masalah-masalah kinerja karyawan. Hal ini bisa disebabkan karena sakit, stres, frustasi dalam pekerjaan dan faktor-faktor lainnya yang pada gilirannya akan mengakibatkan penurunan produktivitas. Sumber daya manusia sebagai aset perusahaan bisa terhambat pendayagunaannya kalau kemangkiran ini tidak ditangani secara serius. Besarnya biaya yang dikeluarkan akan menjadi beban setiap organisasi. Lebih lanjut ditambahkan oleh Pantius D. Soeling (2002), "Pengeluaran tersebut disebabkan karena hilangnya produktivitas, biaya ekstra untuk karyawan pengganti sementara, biaya lembur maupun gaji yang tetap dibayar selama karyawan absen".

Apapun alasannya, kemangkiran karyawan lebih banyak memiliki konsekuensi negatif dari pada positifnya. Oleh karena itu masalah kemangkiran seperti ini perlu didiagnosis untuk mencari sumber penyebabnya. Kalau sudah diidentifikasi baru bisa dilakukan upaya-upaya penanggulangannya. Perilaku kemangkiran berkembang dari moral kerja yang rendah dalam suatu organisasi sehingga motivasi untuk datang kerja juga rendah, selain hal-hal yang tak bisa dihindari (sakit, kecelakaan lalu lintas). PT. Aneka Tuna Indonesia merupakan salah satu perusahaan pengekspor ikan tuna dalam kaleng di Indonesia yang mempunyai ratusan karyawan, juga tidak terlepas dari masalah ketenagakerjaan. Pada beberapa tahun belakangan ini PT. Aneka Tuna Indonesia mengalami tingkat kemangkiran yang tinggi dari karyawannya. Tingkat kemangkiran tersebut terjadi di berbagai departemen pada PT. Aneka Tuna Indonesia di Pasuruan, sehingga hal ini sangat mengganggu jalannya perusahaan. Sedangkan faktor-faktor yang mempengaruhi motivasi seseorang untuk hadir sangatlah bervariasi sehingga perlu ditentukan faktor-faktor apa yang paling berpengaruh. Oleh karena itu penulis merasa tertarik melakukan penelitian untuk mengetahui faktor-faktor motivasi apa yang 
paling dominan mempengaruhi tingkat kemangkiran karyawan. Hasil penelitian ini diharapkan menjadikan masukan bagi perusahaan untuk menetapkan prioritas kebijaksanaan di masa datang agar diperoleh karyawan yang mempunyai loyalitas dan produktivitas kerja yang tinggi.

\section{TINJAUAN PUSTAKA}

Penyebab dan jenis kemangkiran ini bermacam-macam dan dilakukan oleh pekerja dari segala umur dan jenis kelamin. Seringkali alasan-alasan yang dikemukakan oleh karyawan terhadap kemangkirannya cenderung dicari-cari. Alasan yang paling sering diberikan adalah masalah kesehatan. Di Indonesia terlihat pola-pola kemangkiran yang hampir membudaya seperti perayaanperayaan Lebaran, Natal dan Tahun Baru dimana waktu libur cenderung diperpanjang tanpa seijin perusahaan. Lebih parah lagi kalau hari kerja berada diantara dua hari libur seperti libur nasional pada hari jum'at sehingga hari sabtu dianggap hari tanggung untuk bekerja.

Menurut Griffin (2004) menyatakan bahwa : "The cause (illness, jury duty, death in the family) may be legitimate or feignedreported as legitimate but actually just an excuse to stay home".

Tampaknya sebagian besar kemangkiran tidaklah direncanakan terlebih dahulu akan tetapi pada kondisi-kondisi tertentu karyawan cenderung memanfaatkan setiap kesempatan yang memungkinkan untuk mangkir.

Kemangkiran dapat mempunyai dampak negatif maupun positif, seperti misalnya di satu pihak karyawan yang mangkir berarti menunda pekerjaan yang seharusnya telah diselesaikan dan juga menunda pengambilan keputusan sehingga kerja lembur mungkin diperlukan untuk menyelesaikan pekerjaan yang sempat tertunda selama karyawan tidak masuk kerja. Di pihak lain, keputusan karyawan untuk tidak hadir di tempat kerjanya justru menguntungkan karyawan yang bersangkutan karena dapat mengurangi stres akibat tuntutan pekerjaan yang berat atau sekedar menghilangkan rasa jenuh akibat pekerjaan yang monoton.

Menurut Wherther dan Davis (2000) menyatakan bahwa : "Effective department meet both company objectives and employee need. When employee needs are unmet, turnover, absenteeism, and union activity are more likely".

Menurut Leap dan Crino (2006) "Absences occur when an employee fails to report to work as scheduled". Pendapat serupa dikemukakan oleh Flippo (2004) : "Absenteeism is the title given to a condition that exists when a person fails to come to work when properly scheduled to work"

Kemangkiran adalah suatu kondisi yang muncul ketika seorang pekerja tidak hadir ditempat kerjanya sesuai dengan jadwal kerja. Jadi dapat diartikan bahwa kemangkiran/absensi itu secara langsung maupun tidak langsung, mempengaruhi proses manajemen karyawan dalam usaha untuk memperbaiki atau meningkatkan kualitas produksi, karena untuk mengontrol motivasi kerja dan pengambilan keputusan dalam perencanaan kerja, harus mempertimbangkan jumlah jam atau hari kerja yang hilang yang disebabkan oleh kemangkiran.

Adapun Flippo (2004) menegaskan perlunya mengklasifikasikan setiap kemangkiran ke dalam karakteristikkarakteristik dasar sebagai berikut :

1) Name of the employee.

2) Reasons given.

3) Projected reasons.

4) Age.

5) Sex.

6) Date.

Untuk mengetahui sejauh mana tingkat keparahan dari kemangkiran diperlukan suatu pengukuran. Pengukuran tersebut dapat dilakukan melalui berbagai aspek. Magdelena 
L (2008) mengatakan bahwa aspek-aspek tersebut adalah :

1. Frekuensi

2. Aspek orang

3. Aspek \% waktu yang hilang :

4. Aspek rata-rata lamanya absen per orang :

Tingkat kemangkiran karyawan yang wajar adalah antara $2 \%$ sampai $3 \%$ sedang tingkat kemangkiran 3\% sampai 5\% adalah kurang efisien, dan lebih dari 5\% sudah tidak efisien lagi.

Tingkat kenangkiran yang tinggi sangatlah berbahaya, oleh karena itu sebaiknya tiap departemen secara periodik melakukan pencatatan dan penelitian terhadap setiap kemangkiran sehingga didapatkan persoalan sebenarnya mengapa seorang karyawan mangkir.

a. Faktor-faktor yang Mempengaruhi

Kemangkiran

Magdalena L (2008) mengelompokkan sebab-sebab meningkatnya gejala kemangkiran ke dalam tiga faktor yaitu :

1. Faktor lingkungan yang berpengaruh terhadap kemangkiran karyawan mencakup iklim atau cuaca, dan jarak tempat tinggal karyawan yang bersangkutan.

2. Faktor organisasi dan manajemen perusahaan mencakup besarnya organisasi, sikap manajemen terhadap kemangkiran, kebijaksanaan dalam upah, kondisi kerja yang tidak menunjang dan sistem pelayanan kesehatan yang kurang memadai.

3. Faktor pribadi mencakup masa kerja, motivasi dan kepuasan kerja.

Sedangkan Pigors dan Myers (2010) mengemukakan sebab kemangkiran digolongkan dalam dua hal :

1. Variabel exogen, mencakup rutinitas, gaji, peran tanggung jawab keluarga.

2. Variabel endogen, mencakup kepuasan kerja, keterlibatan kerja, status kesehatan.
Sedangkan menurut Cuming (2007) tiga faktor utama yang secara konsisten diasosiasikan dengan tingkat kemangkiran adalah sebagai berikut :

1. Personal, yang dapat dikontrol dalam beberapa hal tertentu melalui kebijaksanaan seleksi dari organisasi, seperti misalnya usia, jenis kelamin, jarak rumah dan tempat kerja, tanggung jawab keluarga.

2. Organizational, yang secara langsung berada di bawah kontrol manajemen lokal, contohnya tingkat kesulitan atau ketidaknyamanan pekerjaan, tingkat stres, pergantian kerja (shift) dan jumlah jam lembur, tingkat pendapatan, dan secara umum adalah moral pekerja.

3. External, faktor-faktor seperti tingkat pengangguran lokal yang secara keseluruhan berada di luar kontrol organisasi individual.

b. Tipe-tipe kemangkiran

Hammer, Landau dan R Stern (1992) membagi kemangkiran ke dalam dua jenis yaitu :

1. Voluntary absenteeism (absen yang disengaja)

2. Involuntary absenteeism (absen karena terpaksa)

Dengan berbagai alasan yang ada, maka dipandang dari sudut organisasi kemangkiran/absen dapat diklasifikasikan menjadi dua yaitu:

1. Kemangkiran secara resmi (dengan seijin) organisasi/perusahaan

2. Kemangkiran tidak resmi (tanpa seijin) organisasi/perusahaan

c. Dampak Kemangkiran

Absen di kalangan karyawan tidak hanya merugikan perusahaan melainkan juga memberikan dampak bagi individu sebagai pekerja maupun sebagai masyarakat pada umumnya. Dari sudut pandang individu, absen mempunyai dampak baik negatif maupun positif, seperti misalnya disatu pihak individu 
yang absen berarti menunda pekerjaan yang seharusnya telah diselesaikan dan juga menunda pengambilan keputusan sehingga kerja lembur mungkin diperlukan untuk memperbaiki ataupun menyelesaikan pekerjaan yang sempat tertunda selama individu tidak masuk kerja. Di lain pihak, keputusan individu untuk tidak hadir di tempat kerjanya dapat menguntungkan individu yang bersangkutan karena individu menghindari stres akibat tuntutan pekerjaan yang terlalu berat atau sekedar menghilangkan rasa jenuh akibat pekerjaan yang monoton.

d. Penanggulangan Kemangkiran

Beberapa usaha penanggulangan absensi dapat difokuskan ke dalam tiga hal pokok :

1. Bagaimana usaha perusahaan untuk meningkatkan kepuasan kerja dengan situasi dan kondisi pekerjaan yang ada.

2. Bagaimana usaha perusahaan untuk meningkatkan tekanan-tekanan agar karyawan mau datang bekerja

3. Bagaimana usaha perusahaan untuk meningkatkan kemampuan karyawan untuk datang bekerja

Pendekatan job enrichment yang lebih terpadu dikemukakan oleh Hackman dan kawan-kawan (2005), ada lima hal pokok yang harus ada dalam pekerjaan :

1. Variasi keahlian dalam pekerjaan itu (job skill) sehingga karyawan dapat memanfaatkan semua keahlian yang dimiliki.

2. Identitas pekerjaan (job identity) sehingga karyawan dapat merasakan ikut memiliki produk yang dihasilkan. Untuk itu karyawan diberikan tugas dan tanggung jawab pembuatan suatu barang dari awal sampai dengan hasil berupa barang jadi.

3. Signifikansi pekerjaan (job significant) dengan cara menumbuhkan rasa kebanggaan atas produk yang dihasilkan. Bahwa produk yang dibuat itu sangat berarti bagi orang lain.
4. Otonomi (autonomy) adalah kebebasan bagi karyawan untuk menentukan sendiri apa yang harus dilakukan. Karena karyawan yang membuat, maka berikanlah tanggung jawab sepenuhnya atas pekerjaan yang telah dilakukan.

5. Umpan balik (feedback) yang segera kepada karyawan setelah produk/jasa yang dihasilkan memberi harapan dan mendapat tanggapan dari masyarakat.

\section{RUMUSAN MASALAH}

Berdasarkan latar belakang yang dijelaskan, rumusan masalah adalah sebagai berikut:

1. Apakah Keluasan pekerjaan secara signifikan mempengaruhi tingkat kemangkiran karyawan operasional PT Aneka Tuna Pasuruan?

2. Apakah Stres peran secara signifikan mempengaruhi tingkat kemangkiran karyawan operasional PT Aneka Tuna Pasuruan?

3. Apakah Ukuran kelompok kerja secara signifikan mempengaruhi tingkat kemangkiran karyawan operasional PT Aneka Tuna Pasuruan?

4. Apakah Gaya kepemimpinan secara signifikan mempengaruhi tingkat kemangkiran karyawan operasional PT Aneka Tuna Pasuruan?

5. Apakah Hubungan antar karyawan secara signifikan mempengaruhi tingkat kemangkiran karyawan operasional PT Aneka Tuna Pasuruan?

6. Apakah Kesempatan untuk berkembang secara signifikan mempengaruhi tingkat kemangkiran karyawan operasional PT Aneka Tuna Pasuruan?

7. Apakah Sistem imbalan/insentif secara signifikan mempengaruhi tingkat kemangkiran karyawan operasional PT Aneka Tuna Pasuruan?

8. Apakah Norma kelompok kerja secara signifikan mempengaruhi tingkat 
kemangkiran karyawan operasional PT Aneka Tuna Pasuruan?

9. Apakah Komitmen pada organisasi secara signifikan mempengaruhi tingkat kemangkiran karyawan operasional PT Aneka Tuna Pasuruan?

\section{TUJUAN PENELITIAN}

Berdasarkan latar belakang penelitian dan rumusan masalah yang telah dijelaskan sebelumnya, tujuan yang ingin dicapai dalam penelitian ini adalah sebagai berikut:

1. Untuk menguji dan menganalisis pengaruh Keluasan pekerjaan pada tingkat kemangkiran karyawan operasional PT Aneka Tuna Pasuruan

2. Untuk menguji dan menganalisis pengaruh Stres peran pada tingkat kemangkiran karyawan operasional PT Aneka Tuna Pasuruan

3. Untuk menguji dan menganalisis pengaruh Ukuran kelompok kerja pada tingkat kemangkiran karyawan operasional PT Aneka Tuna Pasuruan

4. Untuk menguji dan menganalisis pengaruh Gaya kepemimpinan pada tingkat kemangkiran karyawan operasional PT Aneka Tuna Pasuruan

5. Untuk menguji dan menganalisis pengaruh Hubungan antar karyawan pada tingkat kemangkiran karyawan operasional PT Aneka Tuna Pasuruan

6. Untuk menguji dan menganalisis pengaruh Kesempatan untuk berkembang pada tingkat kemangkiran karyawan operasional PT Aneka Tuna Pasuruan

7. Untuk menguji dan menganalisis pengaruh Sistem imbalan/insentif pada tingkat kemangkiran karyawan operasional PT Aneka Tuna Pasuruan

8. Untuk menguji dan menganalisis pengaruh Norma kelompok kerja pada tingkat kemangkiran karyawan operasional PT Aneka Tuna Pasuruan
9. Untuk menguji dan menganalisis pengaruh Komitmen pada organisasi pada tingkat kemangkiran karyawan operasional PT Aneka Tuna Pasuruan

\section{HIPOTESIS}

Berdasarkan rumusan masalah yang diajukan, landasan teoritis, kerangka kerja proses pemikiran dan kerangka konseptual yang diusulkan, hipotesis penelitian dirumuskan sebagai berikut:

H1: Diduga Keluasan pekerjaan secara signifikan mempengaruhi tingkat kemangkiran karyawan operasional PT Aneka Tuna Pasuruan

H2: Diduga Stres peran secara signifikan mempengaruhi tingkat kemangkiran karyawan operasional PT Aneka Tuna Pasuruan

H3: Diduga Ukuran kelompok kerja secara signifikan mempengaruhi tingkat kemangkiran karyawan operasional PT Aneka Tuna Pasuruan

H4: Diduga Gaya kepemimpinan secara signifikan mempengaruhi tingkat kemangkiran karyawan operasional PT Aneka Tuna Pasuruan.

H5: Diduga Hubungan antar karyawan secara signifikan mempengaruhi tingkat kemangkiran karyawan operasional PT Aneka Tuna Pasuruan.

H6: Diduga Kesempatan untuk berkembang secara signifikan mempengaruhi tingkat kemangkiran karyawan operasional PT Aneka Tuna Pasuruan.

H7: Diduga Sistem imbalan/insentif secara signifikan mempengaruhi tingkat kemangkiran karyawan operasional PT Aneka Tuna Pasuruan.

H8: Diduga Norma kelompok kerja secara signifikan mempengaruhi tingkat kemangkiran karyawan operasional PT Aneka Tuna Pasuruan.

H9: Diduga Komitmen pada organisasi secara signifikan mempengaruhi tingkat 
kemangkiran karyawan operasional PT Aneka Tuna Pasuruan.

\section{METODE PENELITIAN}

\section{Identifikasi Variabel}

Variabel-variabel penelitian yang akan diukur sebagai berikut :

a. Variabel Tergantung (Y) yaitu tingkat kemangkiran karyawan dalam periode tertentu

b. Variabel Bebas

$\mathrm{X}_{1}=$ Keluasan pekerjaan

$\mathrm{X}_{2}=$ Stres peran

$\mathrm{X}_{3}=$ Ukuran kelompok kerja

$\mathrm{X}_{4}=$ Gaya kepemimpinan

$\mathrm{X}_{5}=$ Hubungan antar karyawan

$\mathrm{X}_{6}=$ Kesempatan untuk berkembang

$\mathrm{X}_{7}=$ Sistem imbalan/insentif

$\mathrm{X}_{8}=$ Norma kelompok kerja

$\mathrm{X}_{9}=$ Komitmen pada organisasi

\section{Definisi Operasional Variabel}

a. Keluasan pekerjaan $\left(\mathrm{X}_{1}\right)$ ialah jumlah kegiatan yang berbeda yang diperlukan untuk melakukan suatu pekerjaan dan frekuensi kegiatan tersebut dilakukan secara berulang-ulang.

b. Stres peran $\left(\mathrm{X}_{2}\right)$ ialah tingginya konflik yang terjadi pada peran seseorang dalam organisasi.

c. Ukuran kelompok kerja $\left(\mathrm{X}_{3}\right)$ ialah besar kecilnya jumlah anggota suatu kelompok kerja.

d. Gaya Kepemimpinan $\left(\mathrm{X}_{4}\right)$ ialah gaya atau model perilaku pemimpin dalam memimpin bawahan.

e. Hubungan antar Karyawan $\left(\mathrm{X}_{5}\right)$ ialah hubungan yang terjadi diantara para karyawan.

f. Kesempatan untuk Berkembang $\left(\mathrm{X}_{6}\right)$ ialah kejelasan seorang karyawan untuk mendapatkan peluang yang sama dalam memperoleh kesempatan promosi jabatan.

g. Sistem imbalan/insentif $\left(\mathrm{X}_{7}\right)$ ialah sistem imbalan yang dikaitkan dengan kehadiran karyawan. Imbalan yang ditawarkan oleh organisasi harus dipandang dapat dicapai dan mengikat kehadiran secara langsung.

h. Norma-norma kelompok kerja $\left(\mathrm{X}_{8}\right)$ ialah nilai-nilai yang dianut oleh suatu kelompok kerja yang memiliki pengaruh terhadap perilaku individu. Dalam hal ini bagaimana kelompok kerja mempengaruhi individu dalam menekankan pentingnya kehadiran demi kepentingan kelompok.

i. Komitmen pada organisasi $\left(\mathrm{X}_{9}\right)$ Menggambarkan suatu persetujuan dari karyawan terhadap maksud-maksud dan tujuan organisasi dan kemauan untuk bekerja demi mencapai tujuan tersebut.

\section{Jenis dan Sumber Data}

a. Data primer, tentang kondisi PT. Aneka Tuna Indonesia yang diperoleh langsung melalui wawancara dengan pihak-pihak yang berwenang di perusahaan tersebut. Selain itu data primer lainnya diperoleh langsung dari responden melalui observasi dan wawancara langsung dan dengan memberikan kuesioner.

b. Data sekunder, yang diperlukan adalah data jumlah kemangkiran karyawan, data produksi, gambaran umum dan struktur organisasi yang diperoleh dari sumber PT. Aneka Tuna Indonesia dan sumber lain.

\section{Prosedur Penentuan Sampel}

Data sampel yang dibutuhkan dalam penelitian ini diperoleh dengan menggunakan metode penentuan sample combined sampling, yaitu merupakan sampel kombinasi antara purposive sampling dan random sampling. Dalam purposive sampling, pemilihan sampel didasarkan atas ciri-ciri atau sifat-sifat tertentu yang berkaitan erat dengan ciri-ciri responden yang telah ditetapkan, yaitu usia dibawah 55 tahun, masa kerja di atas 1 tahun.

\section{Prosedur Pengumpulan Data}

a. Survey pendahuluan

b. Penelitian lapangan

1) Kuesioner 
2) Wawancara

3) Observasi

4) Dokumentasi

\section{Teknik Analisis}

$Y=\beta_{0}+\beta_{1} X_{1}+\beta_{2} X_{2}+\beta_{3} X_{3}+\beta_{4} X_{4}+\beta_{5} X_{5}$

$+\beta_{6} X_{6}+\beta_{7} X_{7}+\beta_{8} X_{8}+\beta_{9} X_{9}$

Dimana :

$\mathrm{Y}=$ Tingkat kemangkiran

$\mathrm{X}_{1}=$ Keluasan pekerjaan

$\mathrm{X}_{2}=$ Stres peran

$\mathrm{X}_{3}=$ Ukuran kelompok kerja

$\mathrm{X}_{4}=$ Gaya kepemimpinan

$\mathrm{X}_{5}=$ Hubungan antar karyawan

$\mathrm{X}_{6}=$ Kesempatan untuk berkembang

$\mathrm{X}_{7}=$ Sistem imbalan insentif

$\mathrm{X}_{8}=$ Norma kelompok kerja

$\mathrm{X}_{9}=$ Komitmen pada organisasi

$\beta_{0}=$ Konstanta intersep

$\beta_{1}, \beta_{2}, \beta_{3} \ldots \ldots, \beta_{9}=$ Koefisien regresi masingmasing variabel

a. Koefisien Determinasi Berganda $\left(\mathrm{R}^{2}\right)$ dan Koefisien Korelasi Berganda (R)

$$
R^{2}=\frac{S S R}{\text { Total SS }}
$$

Dimana :

SSR : Sum of Squares Regression

Total SS : Total Sum of Squares

Dengan demikian koefisien korelasi berganda (R) dapat dihitung dengan cara :

$$
R=\sqrt{R^{2}}
$$

Semakin dekat nilai $\mathrm{R}^{2}$ dengan 1 , semakin kuatlah model itu dalam menerangkan variasi variabel terikat; semakin dekat nilai $\mathrm{R}^{2}$ dengan 0 maka makin lemahlah model itu dalam menerangkan variasi variabel terikat. Untuk membuktikan kebenaran hipotesa pertama digunakan Uji $\mathrm{F}$, yaitu untuk menguji kebermaknaan nilai koefisien regresi dan korelasi tersebut secara keseluruhan. F hitung dapat diperoleh dengan cara sebagai berikut :

Dimana :

$$
F=\frac{R^{2} / k}{\left(1-R^{2}\right) /(n-k-1)}
$$

$\mathrm{k}$ : banyaknya variabel bebas

$\mathrm{n}$ : ukuran sampel

b. Koefisien Determinasi Parsial $\left(\mathrm{r}^{2}\right)$ dan Koefisien Korelasi Parsial (r)

$$
r \beta^{2}=\frac{t \beta^{2}}{t \beta^{2}+(n-k-1)}
$$

Dimana :

$\mathrm{t} \beta$ : adalah statistik t koefisien $\mathrm{X} \beta$

Dengan demikian koefisien korelasi parsialnya (r), sebagai berikut :

$$
r \beta=\sqrt{r \beta^{2}}
$$

Untuk membuktikan kebenaran hipotesa kedua dan melihat signifikan tidaknya koefisien itu digunakan uji t, dihitung dengan cara :

$$
t \text { hitung }=\frac{\beta i}{S \beta i}
$$




\section{Kerangka Konseptual:}

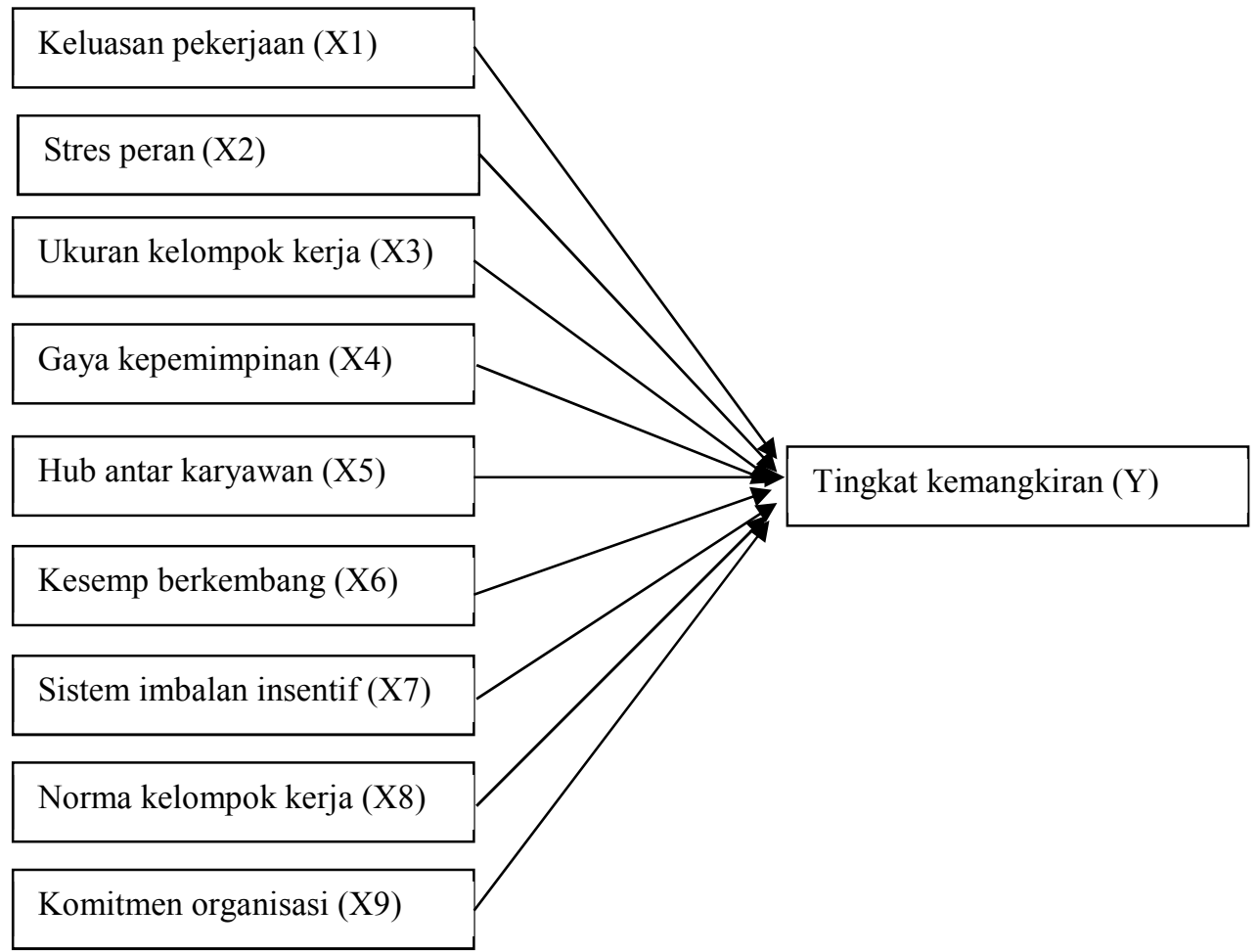

\section{PEMBAHASAN / DISCUSSION}

a. Analisis Regresi Linier Berganda

Dengan menggunakan program SPSS, penulis memperoleh persamaan regresi berganda sebagai berikut : $\mathrm{Y}^{\prime}=29,8280-0,3414 \mathrm{X}_{1}-0,6141 \mathrm{X}_{2}-$ $0,0142 X_{3}-0,0066 X_{4}-0,1033 X_{5}-0,3492 X_{6}$ $-0,0077 \mathrm{X}_{7}-0,0455 \mathrm{X}_{8}-0,0622 \mathrm{X}_{9}$

b. Analisis Regresi Korelasi Linier Berganda Untuk menguji / mengetahui kuat tidaknya hubungan dan pengaruh antara $\mathrm{X}_{1}, \mathrm{X}_{2}, \mathrm{X}_{3}, \mathrm{X}_{4}$, $\mathrm{X}_{5}, \mathrm{X}_{6}, \mathrm{X}_{7}, \mathrm{X}_{8}, \mathrm{X}_{9}$ dengan variabel $\mathrm{Y}$, maka dipergunakan analisis regresi korelasi berganda. Dari hasil perhitungan yang menggunakan program SPSS, penulis mendapatkan nilai koefisien korelasi berganda
(R) dan koefisien determinasi berganda $\left(\mathrm{R}^{2}\right)$ sebagai berikut :

1. Koefisien korelasi $(\mathrm{R})=0,9231$, menunjukkan terdapat hubungan yang kuat/tinggi antara keluasan pekerjaan, stres peran, ukuran kelompok kerja, gaya kepemimpinan, hubungan antar karyawan, kesempatan untuk berkembang, sistem imbalan/insentif, norma kelompok kerja, komitmen pada organisasi dengan variabel kemangkiran. Dapat dikatakan bahwa kesembilan variabel tersebut secara bersama-sama mempunyai korelasi yang tinggi dengan variabel kemangkiran.

2. Koefisien determinasi $\left(\mathrm{R}^{2}\right)=0,8332$, yang berarti $83,32 \%$ kemangkiran yang terjadi 
dipengaruhi oleh faktor keluasan pekerjaan, stres peran, ukuran kelompok kerja, gaya kepemimpinan, hubungan antar karyawan, kesempatan untuk berkembang, sistem imbalan/insentif, norma kelompok kerja, komitmen pada organisasi. Sedangkan sisanya sebesar $16,68 \%$ dipengaruhi oleh faktor lain.

c. Tes Regresi Linier Berganda

Dengan menggunakan program SPSS penulis memperoleh nilai $\mathrm{F}_{0}=44,851$.

Karena $\mathrm{F}_{0}>\mathrm{F}(0,05 ; 9 ; 70)$ yakni $44,077>$ 2,017 maka Ho ditolak. Dengan demikian dapat disimpulkan bahwa :

1. Ho yang menyatakan faktor keluasan pekerjaan, stres peran, ukuran kelompok kerja, gaya kepemimpinan, hubungan antar karyawan, kesempatan untuk berkembang, sistem imbalan/insentif, norma kelompok kerja, komitmen pada organisasi secara bersama-sama

\begin{tabular}{|c|c|c|}
\hline Variabel & $\begin{array}{l}\text { Koefisien } \\
\text { determinasi }\end{array}$ & $\begin{array}{r}\text { Probabi } \\
\text { litas kesalahan }\end{array}$ \\
\hline $\begin{array}{l}\mathrm{X}_{1} \text { (keluasan pekerjaan) } \\
\mathrm{X}_{2} \text { (stres peran) } \\
\mathrm{X}_{3} \text { (ukuran kelompok kerja) } \\
\mathrm{X}_{4} \text { (gaya kepemimpinan) } \\
\mathrm{X}_{5} \text { (hubungan antar karyawan) } \\
\mathrm{X}_{6} \text { (kesempatan untuk berkembang) } \\
\mathrm{X}_{7} \text { ( } \text { (sistem imbalan/insentif) } \\
\mathrm{X}_{8} \text { (norma kelompok kerja) } \\
\mathrm{X}_{9} \text { (komitmen pada organisasi) }\end{array}$ & $\begin{array}{l}\mathrm{r}^{2}=0,7702 \\
\mathrm{r}^{2}=0,6472 \\
\mathrm{r}^{2}=0,0016 \\
\mathrm{r}^{2}=00025 \\
\mathrm{r}^{2}=00039 \\
\mathrm{r}^{2}=0,4831 \\
\mathrm{r}^{2}=0,0014 \\
\mathrm{r}^{2}=0,0057 \\
\mathrm{r}^{2}=0,0081\end{array}$ & $\begin{array}{ll}6 & 0,0002 \\
7 & 0,0005 \\
7 & 0,8892 \\
0 & \\
& 0,9583 \\
4 & \\
2 & 0,3712 \\
3 & 0,0034 \\
9 & 0,9621 \\
9 & 0,6967 \\
6 & \\
5 & 0,6157\end{array}$ \\
\hline
\end{tabular}

e. Test Parsial Regresi Linier Berganda

Berdasarkan hasil perhitungan dengan program SPSS distribusi t diperoleh : mempunyai pengaruh yang tidak bermakna terhadap tingkat kemangkiran, ditolak.

2. Ha yang menyatakan faktor keluasan pekerjaan, stres peran, ukuran kelompok kerja, gaya kepemimpinan, hubungan antar karyawan, kesempatan untuk berkembang, sistem imbalan/insentif, norma kelompok kerja, komitmen pada organisasi secara bersama-sama mempunyai pengaruh yang bermakna terhadap tingkat kemangkiran diterima.

d. Analisis Parsial Regresi Korelasi Berganda

Koefisien determinasi parsial $\left(\mathrm{r}^{2}\right)$ digunakan untuk melihat besarnya sumbangan/pengaruh faktor-faktor secara parsial terhadap kemangkiran. Dari perhitungan dengan menggunakan program SPSS, diperoleh hasil sebagai berikut : 


$\begin{array}{ccccc}\mathrm{t}_{\mathrm{h}} \mathrm{X}_{1}= & -2,270 & \mathrm{t}_{\mathrm{h}} \mathrm{X}_{6} & = \\ -3,029 & & & & \\ & & & & \\ \mathrm{t}_{\mathrm{h}} \mathrm{X}_{2}= & -4,786 & \mathrm{t}_{\mathrm{h}} \mathrm{X}_{7} & = \\ -0,047 & & & & \\ \mathrm{t}_{\mathrm{h}} \mathrm{X}_{3}= & -0,139 & \mathrm{t}_{\mathrm{h}} \mathrm{X}_{8} & = \\ -0,391 & & & & \\ \mathrm{t}_{\mathrm{h}} \mathrm{X}_{4}= & -0,052 & \mathrm{t}_{\mathrm{h}} \mathrm{X}_{9} & = \\ -0,504 & & & & \\ \mathrm{t}_{\mathrm{h}} \mathrm{X}_{5}= & -0,899 & & \\ \text { Masing-masing } & \text { nilai } & \mathrm{t}_{\mathrm{h}} \quad \text { tersebut }\end{array}$
dibandingkan dengan $t_{\text {tabel }}(0,025 ; 9)$ diketahui sebesar 2,262 (pendekatan). Karena menggunakan uji dua ekor maka daerah penolakan Ho adalah : $t_{t}>2,262$ atau $t_{t}<-$ 2,262

\section{KESIMPULAN / CONCLUSSION}

1. Dari persamaan regresi yang diperoleh, dapat diketahui bahwa arah hubungan masing-masing faktor motivasi terhadap variabel kemangkiran, adalah negatif. Artinya semakin tinggi faktor pekerjaan (kepuasan terhadap situasi pekerjaan yang dijelaskan oleh faktor keluasan pekerjaan, stres peran, ukuran kelompok kerja, gaya kepemimpinan, hubungan antar karyawan, kesempatan untuk berkembang, serta tekanan kehadiran yang dijelaskan oleh faktor sistem imbalan/insentifg, norma kelompok kerja, komitmen pada organisasi) untuk hadir bekerja akan diikuti oleh semakin rendahnya tingkat kemangkiran.

2. Dengan menggunakan analisis uji $\mathrm{F}$, dapat disimpulkan bahwa : ada hubungan/pengaruh yang bermakna antara faktor-faktor keluasan pekerjaan, stres peran, ukuran kelompok kerja, gaya kepemimpinan, hubungan antar karyawan, kesempatan untuk berkembang, sistem imbalan/insentif, norma kelompok kerja, komitmen pada organisasi terhadap kemangkiran karyawan. Koefisien korelasi dari variabel tersebut $(\mathrm{R})=0,9231$ menunjukkan adanya hubungan yang kuat/tinggi, sedangkan koefisien determinasi $\left(\mathrm{R}^{2}\right)=0,8332$ berarti $83,32 \%$ kemangkiran yang terjadi dipengaruhi oleh faktor-faktor pekerjaan, sedangkan sisanya sebesar $16,68 \%$ dipengaruhi oleh faktor lain. Dari uraian diatas maka hipotesis yang menyatakan bahwa : "Diduga bahwa faktor-faktor keluasan pekerjaan, stres peran, ukuran kelompok kerja, gaya kepemimpinan, hubungan antar karyawan, kesempatan untuk berkembang, sistem imbalan/insentif, norma kelompok kerja, komitmen pada organisasi mempunyai pengaruh yang bermakna terhadap tingkat kemangkiran karyawan Operasional di PT. Aneka Tuna", terbukti kebenarannya.

3. Dengan menggunakan analisis uji t, disimpulkan bahwa : faktor keluasan pekerjaan, stres peran dan kesempatan untuk berkembang, secara parsial bermakna (signifikan) mempengaruhi kemangkiran karyawan di PT. Aneka Tuna. Sedangkan faktor ukuran kelompok kerja, gaya kepemimpinan, hubungan antar karyawan, sistem imbalan/insentif, norma kelompok kerja, komitmen pada organisasi, secara parsial tidak signifikan mempengaruhi kemangkiran karyawan di PT. Aneka Tuna. Dari hal tersebut dapat dinyatakan bahwa : faktor keluasan pekerjaan mempunyai pengaruh yang dominan daripada faktor-faktor lain, terhadap kemangkiran karyawan di PT. Aneka Tuna.

\section{DAFTAR PUSTAKA}

Alex S. Nitisemito, 1998, Manajemen Personalia, Cetakan Ketiga (Revisi), Ghalia Indonesia, Jakarta.

Cumming, Maurice W., 2007, The Theory and Practice of Personnel Management, William Heinemann Ltd, London. 
Dessler, Gary, 1986, Manajemen Personalia, Edisi Ketiga, Terjemahan, Erlangga, Jakarta.

Firmansyah, M. A., \& Mahardhika, B. W. (2018). Pengantar Manajemen. Deepublish.

Flippo, Edwin B.,2004 Principles of Personnel Management, Fifth Edition, McGraw Hill International Book Company, Singapore.

Gibson, James L, John Ivancevich dan James H. Donnely Jr.,1998 Organisasi dan Manajemen : Perilaku, Struktur, Proses, Terjemahan, Erlangga, Jakarta.

Griffin, Ricky W 2004., Management, Houghton Mifflin Co., Boston, 1987.

Hackman, J.R., G. Oldham, R. Johnson dan K. Pundy, 2005, A New Strategy for Job Enrichment, California Management Review Summer.

Hammer, T.H., J. Landau dan R.N Stern,1992, "Absenteeism when Workers have a Voice : The Case of Employee Ownership", Journal of Applied Psychology, Vol. 66.

Hines, William W., dan Douglas C. Motgomery, 1989 Probabilita dan Statistik dalam Ilmu Rekayasa dan Manajemen, Terjemahan, UI-Press, Jakarta.
Koontz, O’Donnel dan Weihrich, 2000, Management, McGraw Hill, Kosaido Printing Com., Ltf., Tokyo.

Kuma Wijaya, Manajemen Sumber Daya Manusia, Universitas Udayana, Denpasar, 1983.

Leap, Terry L. dan Michael D. Crino, 2006 Personnel / Human Resources Management, Second Edition, Macmillan Publishing Co., New York.

Magdelena Lumbantoruan, 2008, Ensiklopedi Ekonomi, Bisnis dan Manajemen, PT. Cipta Adi Pustaka, Jakarta, 1992.

Pantius D. Soeling, 2002 "Masalah Absenteeism dan Usaha-usaha Penanggulanggannya", Jurnal Ilmu-ilmu Sosial No. 3, Pusat Antar Universitas Bidang Ilmu-Ilmu Sosial Universitas Indonesia, GM. 207.92.658, Jakarta.

Pigors, Paul dan Charles A. Myers,2010, Personnel Administration : A Point of View and A Method, McGraw Hill International Book Co., Tokyo.

Terry, GR, 2001 Prinsip-prinsip Manajemen, Terjemahan, Bumi Aksara, Jakarta.

William B. Werther, Jr., Keith Davis, 2000, Human Resource and Personnel Management, Singapore : Mc Graw - Hill International Edition 